\title{
Hacettepe Üniversitesi Diş Hekimliği Fakültesi'ne Dental İmplant Tedavisi İçin Başvuran Hastaların Cerrahi Öncesi Kaygı Düzeyinin Belirlenmesi
}

\author{
Zuhal Özateş(0000-0002-2419-9793) ${ }^{\alpha}$, Şevket Murat Özbek(0000-0002-8490-6429) ${ }^{\alpha}$, Hasan Gündüz(0000-0002-5495-5844) ${ }^{\beta}$, \\ Banu Cangöz (0000-0003-2213-3261) ${ }^{\beta}$, Emre Tosun(0000-0003-4441-9818) ${ }^{\gamma}$
}

Selcuk Dent J, 2021; 8: 395-401(Doi: 10.15311/selcukdentj.668916)

Başvuru Tarihi: 19 Aralık 2019 Yayına Kabul Tarihi: 17 Mayıs 2020

\begin{abstract}
ÖZ
Hacettepe Üniversitesi Diş Hekimliği Fakültesi'ne Dental İmplant Tedavisi İçin Başvuran Hastaların Cerrahi Öncesi Kaygı Düzeyinin Belirlenmesi
\end{abstract}

Amaç: Diş hekimi ve tedavisine duyulan kaygı insanların sahip olduğu psikolojik durumlardan birisi olarak kabul edilmektedir. Kayglı hastalarda diş hekimliği işlemlerinin gerçekleştirilmesi hem hasta konforu hem de hekimin işlevselliği ve verimi açısından güçlük yaratmaktadır. Bu çalışmada dental implant cerrahisi planlanan hastalarda kaygı düzeyinin belirlenmesi ve hastaların kaygı puanları ile sosyodemografik özellikleri ve implant sayısı arasındaki ilişkinin incelenmesi amaçlanmıştır.

Gereç ve Yöntemler: Çalışmaya dental implant yaptırmak amacıyla başvuran, 30-50 yaş arası, sistemik hastalığı olmayan, nörolojik ya da psikiatrik ilaç kullanmayan toplam 60 gönüllü kadın ve erkek yetişkin katılmıştır. Anket araştırması kapsamında katıımcılara; Demografik Bilgi Toplama Formu, Spilberger Durumluk (DKE) ve Sürekli Kaygı Envanteri (SKE) ve Modifiye Dental Kaygı Ölçeği (MDKÖ) uygulanmıştır.

Bulgular: Üç farklı bağımlı değişken arasındaki ilişkinin belirlenmesi için yürütülen Pearson Korelasyon Analizi sonuçlarına göre tüm gruplar bir arada düşünden üldüğünde DKE' den alınan puanlar ile SKE'den alınan puanlar $(r=.60, p<.000)$ ve MDKÖ' den alınan puanlar arasında $(r=.60, p<.000)$ anlamlı ilişki olduğ raporlanmıştır. Ek olarak cinsiyetin yukarıda adı geçen ölçek puanları üzerinde etkili $(F(3,52)=6.27, p<.001, \eta 2 p=.27)$ bir değişken olduğu sonucuna varılmıştır.

Sonuç: Araştırmada kullanılan üç farklı kaygı ölçeği (DKE, SKE ve MDKÖ) arasında pozitif yönde ve orta düzeyde anlamlı bir ilişki olması, hiç implant uygulanmayan gruptan, tek implant uygulmasına ve 2+ implant uygulamasına doğru gidildikçe hastaların kaygı düzeyinde bir artış olduğunu göstermiştir. Cinsiyet değişkeninin etkili olduğu ve kadınların erkeklere göre implant tedavisinde daha fazla kaygı duydukları sonucuna varımıştır.

\section{ANAHTAR KELIMELER}

Kaygı, Cerrahi, İmplant

Kaygı (anksiyete), fizyolojik uyarılma ile birlikte korku, gerginlik, sinirlilik ve endişe duygularını içeren duygusal durum olarak tanımlanabilir. Kaygı aynı zamanda tehdit edici durumlarla bireyin başa çıkmasına yardımcı

\section{ABSTRACT}

Determination of Preoperative Anxiety Level of Patients Admitted to Hacettepe University Faculty of Dentistry for Dental Implant Treatment

Background: The concern for the dentist and its treatment is accepted as one of the psychological conditions that people have. Performing dental procedures in anxious patients creates difficulties in terms of both patient comfort and the functionality and efficiency of the physician. The aim of this study was to determine the level of anxiety in patients undergoing dental implant surgery and to investigate the relationship between anxiety scores and sociodemographic characteristics and number of implants.

Methods: A total of 60 volunteer male and female adults, between 30 and 50 years of age who had no systemic disease and who did'nt use neurological or psychiatric drugs, were included in the study. Within the scope of the survey research; Demographic Information Collection Form, Spilberger State (SAI) and Trait Anxiety Inventory (TAI) and Modified Dental Anxiety Scale (MDAS) were applied.

Results: According to the results of Pearson Correlation Analysis conducted to determine the relationship between three different dependent variables, the scores obtained from the SAl and the scores from the TAl $(r=.60, p<.000)$. and MDAS scores $(r=.60, p<.000)$. In addition, it was concluded that gender was an influential variable $(F(3,52)=6.27, p$ $<.001, \eta 2 p=.27$ ) on the scale scores mentioned above.

Conclusion: The positive and moderately significant relationship between the three anxiety scales used in the study (SAI, TAI, MDAS) showed that there was an increase in the anxiety level of patients when moving from single implant to $2+$ implant applications. It was concluded that the gender variable was effective and women were more concerned about implant treatment than men.

\section{KEYWORDS}

davranışlar olarak da ifade edilmektedir. ${ }^{1}$ Spielberger ve arkadaşlarına ${ }^{1}$ göre kaygı durumluk ve sürekli kaygı olarak iki temel bileşene ayrılır. Durumluk Kaygı: Bireyin içinde bulunduğu stresli durumdan

\footnotetext{
${ }^{\alpha}$ Hacettepe Üniversitesi Diş Hekimliği Fakültesi Ağız, Diş ve Çene Radyolojisi AD. Ankara, Türkiye

$\beta$ Hacettepe Üniversitesi Edebiyat Fakültesi Psikoloji Bölümü, Ankara, Türkiye

${ }^{\vee}$ Hacettepe Üniversitesi Diş Hekimliği Fakültesi Ağız, Diş ve Çene Cerrahisi AD. Ankara, Türkiye
} 
dolayı hissettiği sübjektif korkudur. Fizyolojik olarak da otonom sinir sisteminde meydana gelen bir uyarılma sonucu terleme, sararma, kızarma, titreme gibi fiziksel değişimler bireyin gerilim ve huzursuzluk duygularının göstergesidir. Stresin yoğun olduğu zamanlar durumluk kaygı seviyesinde yükselme stres ortadan kalkınca düşme olur. Sürekli Kaygı: Bireyin kaygı yaşantısına yatkınlığıdır. Buna kişinin içinde bulunduğu durumları genellikle stresli olarak algılama ya da stres olarak yorumlama eğilimi de denebilir. Bu tür kaygı seviyesi yüksek olan bireylerin kolaylıkla incindikleri ve karamsarlığa büründükleri görülür. Bu bireyler durumluk kaygıyı da diğerlerinden daha sık ve yoğun bir şekilde yaşarlar.2 Diş tedavisi öncesi veya sırasında hastaların deneyimlediği kaygı, dışsal ve içsel uyarıcılara karşı oluşan fizyolojik aktivasyon ile ilişkili karmaşık bir davranış biçimi olarak tanımlanmaktadır.3 Dental kaygı ve korku, hemen hemen tüm toplumlarda oldukça yaygın bir sorundur. Diş hekimliği uygulamalarına yönelik kaygı, farklı bileşenleri olan karmaşık bir psikolojik olgudur. Hastaların yaşları, cinsiyetleri, eğitim durumları, yaşadıkları ortam ve geçmişte travmatik diş hekimliği uygulamaları yaşamış olmaları gibi deneyimler dental kaygı seviyelerini etkilemektedir.4 Dental kaygı yaygın korkular arasında dördüncü, yoğun korkular arasında dokuzuncu sırada değerlendirilmektedir.5 Birçok diş hekimliği işlemi öncesi hastalar çeşitli düzeylerde kaygı hissetmekle birlikte, ağız cerrahisi işlemleri en yüksek kaygı seviyesi ile ilişkilendirilmektedir.6,8 Hastalar ve diş hekimleri açısından önemli bir komplikasyon olan dental kaygı, hastaların diş hekimi ziyaretlerini ertelemelerine, iptal etmelerine ya da tedaviden tamamen kaçınmalarına ve verim kaybına yol açmaktadır.9,10 Dental kaygıya sahip hastaların, diğer hastalarla karşılaştırıldığında, daha fazla çürük, periodontal problem veya daha az dolgulu dişlere sahip oldukları bildirilmiştir.11 Dental implant ameliyatları günümüzde sık gerçekleştirilen ağız cerrahisi işlemlerinden biridir.12 Bütün cerrahi işlemlerde olduğu gibi implant ameliyatında da komplikasyonlar görülebilmektedir. Fakat hayatı tehdit edici komplikasyonlar çok nadir olup, iyileşme süreci nispeten kısadır. İmplant cerrahisinde komplikasyon riskini en aza indirmek ve hasta memnuniyetini artırmak için bireylerin kaygı düzeylerinin belirlenmesi ve buna uygun önlemlerin alınması önemlidir.

\section{GEREÇ VE YÖNTEMLER}

$\mathrm{Bu}$ çalışmaya Hacettepe Üniversitesi Diş Hekimliği Fakültesi'ne başvuran, yaşları 30-50 arasında değişen 30 kadın ve 30 erkek toplam 60 gönüllü yetişkin katılmıştır.

\section{Araştırma Grupları:}

1. Grup: Hiç implant tedavisi görmemiş (kontrol grubu)

2. Grup: Ilk kez ve tek implant tedavisi gören (hasta grubu 1)
3. Grup: Ilk kez ve iki veya daha fazla implant tedavisi gören (hasta grubu 2)

Çalışma protokolü, Hacettepe Üniversitesi Girişimsel Olmayan Klinik Araşrırmalar Etik Kurul Komitesi tarafından onaylanmıştır (11.12.2018-16969557-2226). Araştırmanın tüm gruplarındaki katılımcılar, sistemik hastalığı, psikiyatrik veya nörolojik hastalığı olmayan, psikiatrik ilaç kullanmayan yetişkinlerdir. Çalışmanın amacı konusunda kısa bir bilgilendirme yapıldıktan sonra, katılımcılara aydınlatılmış onam formu verilmiştir. Hastaların yaş, cinsiyet, eğitim durumu, diş hekimi ziyareti sebebi gibi bilgilerin olduğu Demografik Bilgi Toplama Formu, kaygı düzeyini belirlemek için DKE ve SKE ve MDKÖ uygulanmıştır. Ölçeklerin uygulanış sırası her defasında seçkisiz olarak belirlenmiştir.

Verilerin Analize Hazırlanması ve Varsayımların Test Edilmesi

Katılımcılardan elde edilen puanlar için her bir grup kendi içerisinde değerlendirilerek z puanları hesaplanmıştır. Z puanı $[-3,3]$ aralığı dışında yer alan herhangi bir uç veri bulunmamıştır. Veriler tarandığında, her biri bir ölçek maddesi olmak üzere toplamda 3 adet kayıp veri tespit edilmiştir. O kayıp veriye sahip olan katılımcının dahil olduğu grubun (örn. hiç implant tedavisi almamış ve kadın) ilgili ölçek maddesine ilişkin ortalama puanı, kişinin kayıp verisi yerine atanmıştır. Yapılan düzenlemeleri takiben, her bir bağımsız değişken düzeyi için DKE, SKE ve MDKÖ puanları hesaplanmış ve elde edilen veriler, Sosyal Bilimler için İstatistik Paketi (SPSS) 23.0 programı kullanılarak analiz edilmiştir.

\section{Korelasyon Analizi Sonuçları}

Üç farklı bağımlı değişken arasındaki ilişkinin belirlenmesi için yürütülen Pearson Korelasyon Analizi sonuçlarına göre tüm gruplar bir arada düşünüldüğünde DKE' den alınan puanlar ile SKE' den alınan puanlar $(r=.60, p<$ .000) ve MDKÖ'den alınan puanlar arasında $(r=.60, p<$ .000) anlamlı ilişkiler olduğu raporlanmıştır (Tablo 1).

Tablo 1.

Bütün katılımcıların DKE, SKE ve MDKÖ' den aldıkları toplam puanlar arasındaki korelasyon katsayıları ve anlamlılık düzeyleri

\begin{tabular}{cccc} 
& DKE & SKE & MDA \\
\hline DKE & - & & \\
\hline SKE & .597 & - & \\
& $p<.000$ & & - \\
\hline MDA & $\begin{array}{c}.588 \\
p<.000\end{array}$ & .312 & \\
\hline
\end{tabular}

Bu sonuçlara göre DKE'den alınan puanlar arttıkça SKE ve MDKÖ' den alınan puanların da arttığı görülmüştür. Tüm katılımcılardan elde edilen verilere dayanan bu örüntünün benzer şekilde her bir alt grup için de korunduğu gözlemlenmiştir (Tablo 2, 3, 4 ve Şekil 2, 3). 
Tablo 2.

Hiç implant tedavisi görmemiş bireylerin DKE, SKE ve MDKÖ' den aldığı toplam puanlar arasındaki korelasyon katsayıları ve anlamlılık düzeyleri

\begin{tabular}{cccc} 
& DKE & SKE & MDA \\
\hline DKE & - & \\
\hline SKE & .510 & \\
\hline MDA & $p<.05$ & - \\
\hline
\end{tabular}

Tablo 3.

İlk kez ve tek implant tedavisi gören bireylerin DKE, SKE ve MDKÖ' den aldıkları toplam puanlar arasındaki korelasyon katsayıları ve anlamlılık düzeyleri

\begin{tabular}{c|ccc} 
& DKE & SKE & MDA \\
\hline DKE & - & \\
\hline SKE & .502 & - \\
\hline MDA & $\begin{array}{c}.586 \\
p<.005\end{array}$ & .334 & - \\
\hline & & $p<.05$ & - \\
\hline
\end{tabular}

Tablo 4.

İlk kez ve iki veya daha fazla implant tedavisi gören bireylerin DKE, SKE ve MDKÖ' den aldıkları toplam puanlar arasındaki korelasyon katsayıları ve anlamlılık düzeyleri

\begin{tabular}{|c|c|c|c|}
\hline & DKE & SKE & MDA \\
\hline DKE & - & & \\
\hline \multirow{2}{*}{ SKE } & .741 & - & \\
\hline & $\mathrm{p}<.000$ & & \\
\hline \multirow{2}{*}{ MDA } & .658 & .626 & - \\
\hline & $\mathrm{p}<.01$ & $\mathrm{p}<.01$ & \\
\hline
\end{tabular}

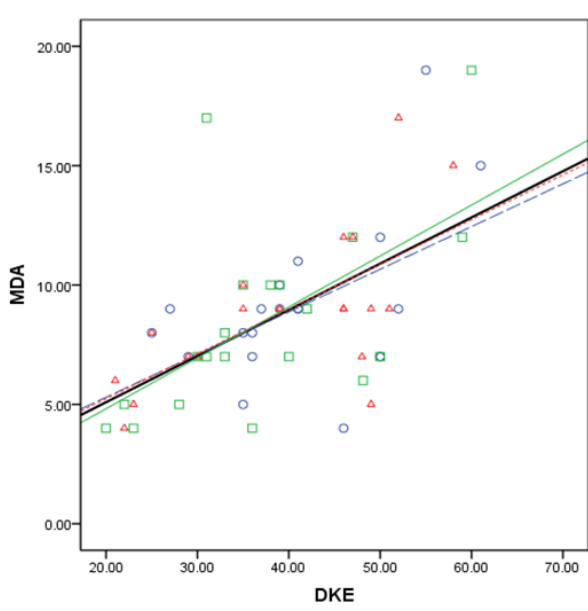

Şekil 2

Üç farklı gruba ait DKE ve MDKÖ puanları arasındaki ilişkiye ilişsin grafik (A $=$ Hiç implant teravisi görmemiş bireyler, $\mathrm{B}=$ Illk kez ve tek implant tedavisi gören bireyler, $\mathrm{C}=$ Illk kez ve iki veya daha fazla implant tedavisi gören bireyler)

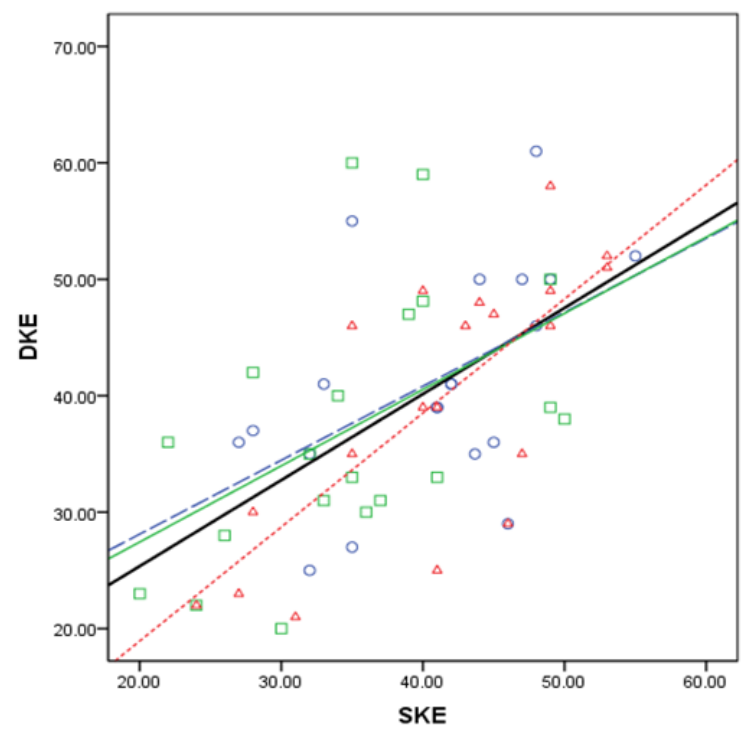

Şekil 3

Üc farklı gruba ait SKE ve DKE puanları arasındaki ilișkiye ilișkin grafik (A = Hiç implant tedavisi görmemiş bireyler, $\mathrm{B}=$ İlk kez ve tek implant tedavisi gören bireyler, $\mathrm{C}=$ İlk kez ve iki veya daha fazla implant tedavisi gören bireyler)

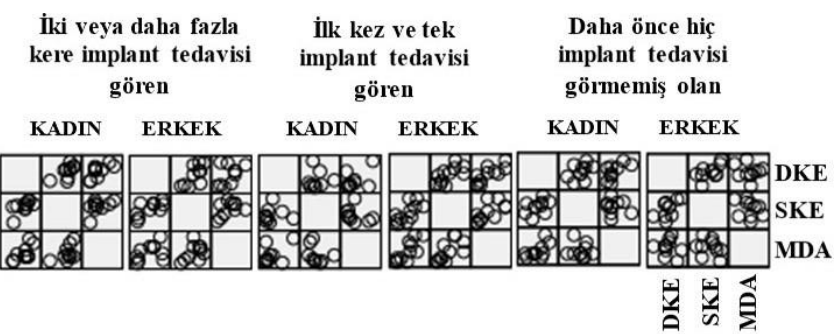

Şekil 4

Bağımsız değişkenlerin her bir düzeyi için DKE, SKE ve MDA arasındaki doğrusal ilişkiler

SKE' den elde edilen puanlar ve MDKÖ' den elde edilen puanlar arasında tüm gruplar bir arada incelendiğinde anlamlı bir iliş̧ki söz konusudur $(r=.31$, $p<.05)$. Bu sonuçlara göre iki puan birlikte azalıp artma eğilimi göstermektedir. Aynı puanlar arasındaki bu ilişkinin anlamlı olduğu tek alt grup ise iki ya da daha fazla implant tedavisi gören bireyler olmuştur $(r=.63, p$ $<.01$ ). SKE ve MDKÖ puanları arasında diğer iki katı ımcı grubunda anlamlı bir ilişkinin gözlemlenmemesi (Tablo 2, 3), tüm bireyler bir arada düşünüldüğünde anlamlı bulunan bu ilişkinin kaynağının iki veya daha fazla implant tedavisi gören bireyler olduğu görülmektedir (Şekil 1) 


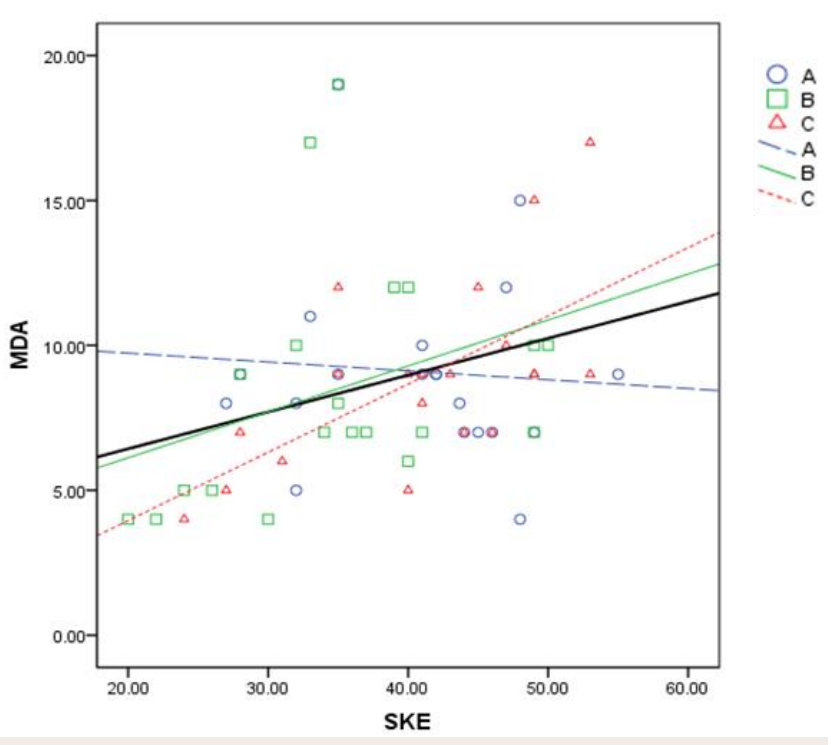

Șekil 1

Üç farklı gruba ait SKE ve MDKÖ puanları arasındaki ilişkiye ilişkin grafik (A = Hiç implant tedavisi görmemiş bireyler, $\mathrm{B}=$ İlk kez ve tek implant tedavisi gören bireyler, $\mathrm{C}=$ İlk kez ve iki veya daha fazla implant tedavisi gören bireyler)

\section{MANOVA Analizi Varsayımlarının Test Edilmesi}

Elde edilen verilerin 3 (Grup: Hiç implant tedavisi görmemiş bireyler, İlk kez ve tek implant tedavisi gören bireyler ve Illk kez ve iki veya daha fazla implant tedavisi gören bireyler) x 2 (Cinsiyet: Kadın ve Erkek) desenine uygun parametrik bir analiz tekniği olan MANOVA'nın varsayımlarını karşılayıp karşılamadığı test edilmiştir. Öncelikle bu testin yürütülmesi için elde edilen ölçümlerin eşit aralıklı ya da oranlı ölçeklerden elde edilen ölçümler olması gerekmektedir. DKE, SKE ve MDKÖ ölçeklerinden elde edilen ölçümler eşit aralıklı ölçümler olarak değerlendirildiğinden bu varsayım karşılanmıştır. Başka bir varsayım ise bağımsız değişkenlerin her bir düzeyi için bağımlı değişkenler arasında doğrusal bir ilişki olması gerekliliğidir. Bu varsayım test edilmiş ve ilişkilerin doğrusal olduğu gösterilmiştir (Şekil 4) Ayrıca bağımlı değişkenler arasında çoklu doğrusallık problemi (multicollinearity) olup olmadığı bağımlı değişkenler üzerinden yapılan korelasyon analizi ile incelenmiş ve ilişki katsayılarının her birinin olması gereken aralıkta $(r=.20$ ve $r=.80$ aralığı) olduğu gösterilmiştir (Tablo 5).

Tablo 5.

Bütün katılımcıların DKE, SKE ve MDKÖ’ den aldıkları toplam puanlar arasındaki korelasyon katsayıları ve anlamlılık düzeyleria

\begin{tabular}{|c|c|c|c|}
\hline & DKE & SKE & MDA \\
\hline DKE & - & & \\
\hline \multirow{2}{*}{ SKE } & .597 & & \\
\hline & $p<.000$ & & \\
\hline \multirow{2}{*}{ MDA } & .588 & .312 & \\
\hline & $p<.000$ & $p<.05$ & 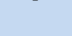 \\
\hline
\end{tabular}

Uç verilere ilişkin yapılan regresyon analizi ile hiç bir veriye ait mahalanobis mesafesinin olması gereken kritik değeri (3 bağımlı ölçüm için 16.27) geçmediği tespit edilmiştir. Varyans ve kovaryans matrikslerinin benzerliği ise analiz sonucunda elde edilen Box' un Kovaryans Matrikslerinin Eşitliği Testi sonucunda kontrol edilmiş ve sonucun anlamlı olmadığı (Box's M $=29.78, p>$.05), matrikslerin olması gerektiği gibi benzer oldukları gösterilmiştir. Çoklu normallik sayıltısı her bir bağımsız değişken için Shapiro-Wilk testi $(n<50)$ ile incelenmiştir. Cinsiyetle ilgili sonuçlar incelendiğinde, sadece hem kadınlardan elde edilen MDKÖ verilerinin (S-W $=.82, p<.001)$ hem de erkeklerden elde edilen MDKÖ verilerinin $(S-W=.93$, $p<.05)$ bu varsayımı karşılamadığı görülmüştür. Aynı inceleme grup bağımsız değişkeni temelinde yapıldığında da benzer şekilde yine daha önce implant tedavisi görmemiş bireylerden elde edilen MDKÖ verileri $(\mathrm{S}-\mathrm{W}=.86, \mathrm{p}<.01)$ ile ilk kez ve tek implant tedavisi gören bireylerden elde edilen MDKÖ verilerinin $(\mathrm{S}-\mathrm{W}=.88, \mathrm{p}<.05)$ bu varsayımı karşılamadığı gösterilmiştir. İki bağımsız değişkenin diğer tüm düzeylerinde elde edilen tüm bağımlı ölçümler normallik sayıltısını karşılamıştır (Şekil 4).

Yapılan detaylı incelemeler sonunda bir çok varsayım sağlanmış olmasına rağmen normallik varsayımında karşılaşılan sorun nedeniyle MANOVA analizi sonucunda varsayımlar konusunda daha katı bir test olan Pillai's Trace' e ait sonuçlar raporlanmıştır.

Katılımcılardan Elde Edilen DKE, SKE ve MDKÖ Puanları Üzerinden Yapılan 3(Grup: Hiç İmplant Tedavisi Görmemiş Bireyler, Illk Kez Ve Tek İmplant Tedavisi Gören Bireyler, Illk Kez Ve İki Veya Daha Fazla Implant Tedavisi Gören Bireyler) X 2(Cinsiyet: Kadın Ve Erkek) MANOVA Analizi Sonucu

İki bağımsız değişkenin her bir düzeyinde katılımcıların DKE, SKE ve MDKÖ ölçeklerinden aldıkları puanların ortalama ve standart sapma değerleri aşağıdaki tablolarda özetlenmiştir (DKE için Tablo 6, SKE için Tablo 7, MDKÖ için Tablo 8).

\section{Tablo 6.}

İki Bağımsız Değişkenin Her Bir Düzeyinde SKE' den Alınan Puanların Ortalama ve Standart Sapma Değerleri

\begin{tabular}{|c|l|l|}
\hline \multicolumn{1}{|l|}{ Grup } & Cinsiyet & Ortalama \pm Standart Sapma \\
\hline \multirow{2}{*}{ Kontrol } & Kadın $(n=10)$ & $44.30 \pm 11.18$ \\
& Erkek $(n=10)$ & $38.20 \pm 6.78$ \\
& Toplam $(n=20)$ & $41.25 \pm 9.35$ \\
\hline \multirow{2}{*}{ Ilk kez ve tek implant } & Kadın $(n=10)$ & $37.68 \pm 10.04$ \\
Grubu & Erkek $(n=10)$ & $36.61 \pm 12.58$ \\
\cline { 2 - 3 } Ik kez ve 2+ Implant & Toplam $(n=20)$ & $37.26 \pm 11.22$ \\
Grubu & Kadın $(n=10)$ & $44.30 \pm 9.73$ \\
& Erkek $(n=10)$ & $34.70 \pm 11.19$ \\
\hline \multirow{2}{*}{ Toplam } & Toplam $(n=20)$ & $39.50 \pm 11.33$ \\
& Kadın $(n=30)$ & $42.25 \pm 10.45$ \\
& Erkek $(n=30)$ & $36.61 \pm 10.30$ \\
& Toplam $(n=60)$ & $39.33 \pm 10.67$ \\
\hline
\end{tabular}


Tablo 7.

\section{Çocuklarla Ebeveynleri Arasında Dişlerin Düzgünlüğüne Dair Algı Oranlarının Karşılaştırıması}

\begin{tabular}{|c|c|c|}
\hline Grup & Cinsiyet & Ortalama \pm Standart Sapma \\
\hline \multirow{3}{*}{ Kontrol } & $\operatorname{Kadin}(n=10)$ & $42.20 \pm 7.77$ \\
\hline & Erkek $(n=10)$ & $39.17 \pm 7.63$ \\
\hline & Toplam $(n=20)$ & $40.68 \pm 7.66$ \\
\hline \multirow{3}{*}{$\begin{array}{l}\text { Illk kez ve tek implant } \\
\text { Grubu }\end{array}$} & Kadın $(n=10)$ & $37.67 \pm 5.48$ \\
\hline & Erkek $(n=10)$ & $32.82 \pm 10.25$ \\
\hline & Toplam $(n=20)$ & $35.00 \pm 8.61$ \\
\hline \multirow{3}{*}{$\begin{array}{c}\text { Illk kez ve 2+ Implant } \\
\text { Grubu }\end{array}$} & Kadın $(n=10)$ & $46.20 \pm 7.15$ \\
\hline & Erkek $(n=10)$ & $35.80 \pm 6.65$ \\
\hline & Toplam $(n=20)$ & $41.00 \pm 8.58$ \\
\hline \multirow{3}{*}{ Toplam } & Kadın $(n=30)$ & $42.17 \pm 7.53$ \\
\hline & Erkek $(n=30)$ & $35.83 \pm 8.53$ \\
\hline & Toplam $(n=60)$ & $38.89 \pm 8.61$ \\
\hline
\end{tabular}

Tablo 8.

\section{Çocuklarla Ebeveynleri Arasında Dişlerin Beyazlığına Dair Algı Oranlarının Karşılaştıııması}

\begin{tabular}{|c|c|c|c|}
\hline \multirow{2}{*}{ Grup } & \multicolumn{2}{|c|}{ Dişlerin renginin beyaz olduğunu düşünüyor musunuz? } & \multirow{2}{*}{$\mathbf{P}$} \\
\hline & Evet $n(\%)$ & Hayır $n(\%)$ & \\
\hline Ebeveyn & $16(\% 26.67)$ & $44(\% 73.33)$ & \multirow[t]{2}{*}{$0.003^{*}$} \\
\hline Çocuk & $32(\%$ 53.33) & $28(\%$ 46.67) & \\
\hline
\end{tabular}

Yukarıdaki tablolarda raporlanan ortalama değerler üzerinden yapılan analiz sonucunda sadece Cinsiyet değişkeninin düzeyleri arasında bağımlı değişkenlerin doğrusal kombinasyonlarına göre bir fark olduğu gösterilirken (Pillai's Trace $=.27, \mathrm{~F}(3,52)=6.27, \mathrm{p}<$ $.001, \eta 2 p=.27)$, grup değişkeni ve Grup*Cinsiyet ortak etkisi için bir anlamlılık elde edilmemiştir (Tablo 7).

Not: Tablodaki değerler Pillai's Trace değerleridir.

Anlamlı sonuca ulaşmayan değişkenler için yorumlamalara devam edilmemiş, sadece Cinsiyet değişkeni için elde edilen anlamlı farkın hangi bağımlı değişken ya da değişkenlerle ilişkili olduğu incelenmiştir. Sonuçlara göre cinsiyet bağımsız değişkeninin DKE puanları üzerindeki $(F(1,54)=4.12$, $p<.05, \eta 2 p=.07)$, SKE puanları üzerindeki $(F(1,54)$ $=9.32, p<.01, \eta 2 p=.15)$ ve MDKÖ puanları üzerindeki $(F(3,52)=11.43, p<.001, \eta 2 p=.17)$ temel etkisinin anlamlı olduğu görülmüştür (Tablo 8).

Her bir bağımlı ölçüm için cinsiyet farkları incelenmiştir. Bonferroni düzeltmeli sonuçlara göre kadın katıımcıların DKE' den aldıkları puanın (ORT $=42.09$, $\mathrm{SH}=1.94$ ), aynı ölçekten erkek katıımcıların aldıkları puanın (ORT $=36.60, \mathrm{SH}=1.88$ ) anlamlı olarak yüksek olduğu bulunmuştur $(p<.05)$. SKE' den alınan ortalama puanlar incelendiğinde de benzer şekilde kadın katılımcıların bu ölçekten elde ettikleri puanın (ORT $=42.02, \mathrm{SH}=1.43)$, erkek katılımcıların elde ettikleri SKE puanından (ORT $=35.93, \mathrm{SH}=1.39$ ) anlamlı olarak yüksek olduğu görülmüştür $(p<.01)$. MDKÖ puanları üzerindeki cinsiyet temel etkisi incelendiğinde yine kadın katılımcıların MDKÖ puanlarının erkeklerden anlamlı olarak yüksek olduğu bulunmuştur ( $p<.001$, bkz. Şekil 5). MDKÖ puanlarının erkeklerden anlamlı olarak yüksek olduğu bulunmuştur ( $p<.001$, Şekil 5$)$.

\section{GEREÇ VE YÖNTEMLER}

Dental kaygının ölçümü, diş hekimliği uygulamalarının başarısı ve verimliliğinin artırıması ile hasta memnuniyeti açısından hastaların genelde kaygı, özelde dental kaygı düzeylerinin belirlenmesi gereklidir. ${ }^{13}$ Dental kaygının ölçümünde yaygın bir uygulama olarak, hastalara anket soruları yöneltilmektedir. Buna karşın anketler yerine geçerlik ve güvenirlik çalışmaları yapılmış olan ölçek tipi yapılandırımış standart ölçeklerin kullanılması sonuçların güvenirliği ve objektifliği açısından tercih edilmelidir. Bu bağlamda, yetişkinlerde diş hekimliği uygulamaları için Corah Dental Kaygı Ölçeği ve Spielberg'in Durumluk ve Sürekli Kaygı Envanteri kullanılmaktadır. Bu çalışmada SKE ve DKE ile MDKÖ kullanılmıştır. Literatürde, ağız cerrahisi ve dental kaygı ilişkisinin farklı yönlerden değerlendirildiği çalışmalar bulunmaktadır. ${ }^{3,6,12}$ Örneğin, Marakoğlu ve ark. ${ }^{14}$ yaptıkları çalışmada, dental kaygının sıklıkla kadınlarda, 20 yaş altı çocuk ve gençlerde, eğitim seviyesi düşük, kırsalda yaşayan ve daha önce herhangi bir diş tedavisi yaptırmamış hastalarda daha sık oluştuğunu rapor etmişlerdir. Oktay ve ark. ${ }^{15}$ da yaptıkları bir başka çalışmada yaş grupları arasında kaygı puanları bakımından anlamlı bir fark olmadığını ve yine diğer çalışmaların aksine 20-29 yaş grubunda en düşük kaygı değerini gözlediklerini bildirmişlerdir. Eli ve ark. ${ }^{16}$ implant yerleşimi öncesi, sırası ve sonrasında dental ve durumluk kaygı düzeyinin ağrı yanıtı üzerine etkisini değerlendirdikleri çalışmada kaygı seviyesinin kadınlarda erkeklere göre daha fazla olduğunu bildirmişlerdir. Çalışmaların büyük çoğunluğunda kadın hastaların dental kaygı düzeyleri erkeklere göre daha yüksek bulunmuştur. Çalışmamızda cinsiyetin tüm ölçek puanları üzerinde etkili olduğu yani kadınların istatistiksel olarak anlamlı düzeyde implant tedavisinden daha fazla kaygı duydukları sonucuna varılmıştır. Kadınlarda dental kaygının daha fazla olması, beyindeki yapısal özelliklerin her iki cinsiyette farklılık göstermesinden kaynakladığı düşünülerek yapılan bir görüntüleme çalışmasında, dental kaygısı olan erkek ve kadınların provakatif testlere cevaplarında, beynin farklı bölgelerinin etkin olduğu saptanmıştır. ${ }^{17}$ Kadınların daha yüksek dental kaygıya sahip olduklarını gösteren çalışmalarda, buna neden olarak kadınların ağrı uyaranına erkeklere göre toleransının daha düşük olması gerekçe gösterilmektedir. Ayrıca erkeklerin kaygılarını açık şekilde dile getirmekten çekindikleri kabul edilmektedir. ${ }^{18}$ Çalışmamızın sonuçlarına göre 
kaygı puanı ortalamasının yaş ile ilişkisi istatistiksel olarak anlamlı bulunmamışır. Bizim çalışmamızda yapılan dental implantın sayısı ve kaygı puanları arasındaki ilişki incelendiğinde tek implant yapılan hastalarla ikiden fazla implant uygulanacak hastalarda kaygı durumunda anlamlı bir fark gözlenmemiştir. Çalışmamızda da sistemik hastalıklar, implant sayısı, yapılan tedavi işlemin tipi eğitim düzeyi değişkenleri ile kaygı puanları arasında ilişki saptanmazken, cinsiyet değişkeni açısından gruplar arasında anlamlı bir fark olduğu saptanmıştır. Cinsiyete ait bu bulgu diğer benzer çalışmaları destekler niteliktedir. Ağız cerrahisi ve dental kaygı ilişkisinin farklı yönlerden değerlendirildiği çalışmalar bulunmaktadır. Wilson ve ark. ${ }^{19}$ ağız cerrahisinin genellikle kaygı ile ilişkili olduğunu ancak lokal anestezi ile birlikte kullanılacak bilinçli sedasyon uygulamalarının hastaların oral cerrahiye yönelik kaygı ve ağrı skorlarında önemli ölçüde düşüş sağlayarak ağız sağlığına katkıda bulunabileceğini bildirmiştir. Muğlalı ve Kömerik ${ }^{20}$ yapmış oldukları çalışmada ağız cerrahisi öncesi ve sonrasında kaygıya etki eden faktörleri değerlendirmiş; çenede yorgunluk oluşması ve ağızda sıvı birikimini hastaların kaygı duyduğu durumlar olarak saptamışlardır. Ağız cerrahisi uygulamalarında bu hususlara dikkat edilmesinin hastaların tedavilerini daha kolay hale getirebileceğini ifade etmişlerdir. Bir diğer çalışmada ağız cerrahisi geçirecek hastalara operasyon öncesi, operasyona ve cerrahi sonrası iyileşme dönemine ilişkin bilgilendirme yapılmasının kaygı seviyesinde ciddi düzeyde azalma oluşturabileceği bildirilmiş̧ir. Ağız cerrahisinde kullanılan gelişmiş ekipmanların ve sedasyon uygulamalarının dental kaygıyı azaltmada etkili olabileceği ve tedavinin kabul edilebilirliğini artırabileceği gösterilmiştir. Yapılan çalışmalarda kaygı düzeyi yüksek olan hastaların daha fazla dental problemi olduğu gibi daha az dental tedaviye sahip olduğu bildirilmiştir. ${ }^{21}$ Hekimlerin tüm koşullar altında hastanın kaygı duygusunu azaltıcı yaklaşımlarda bulunması, özellikle de kaygı düzeyi yüksek hastalara özen göstermesi gerektiği açıktır. Kaygı düzeyini azaltmak için yapılabilecek uygulamalar arasında hastanın işlem konusunda bilgilendirilmesi, ortamın rahatlatıcı olmasının sağlanması, hastaya güven verilmesi ve gerektiği durumlarda sedatif ajanların kullanılması sayılabilir. Birçok diş hekimliği işlemi öncesi hastalar çeşitli düzeylerde kaygı hissetmekle birlikte, cerrahi sonrası ağrı, kanama, şişlik, ağız açıklığında azalma ve normal günlük aktivitelerde kısıtlanma ile bağlantıı bulunan ağız cerrahisi işlemleri en yüksek kaygı seviyesi ile ilişkilendirilmektedir. ${ }^{22,23}$

\section{SONUÇ}

Araşıımada kullanılan üç farklı kaygı ölçeği (DKE, SKE ve MDKÖ) arasında pozitif yönde ve orta düzeyde anlamlı bir ilişki olması bireylerin genel kaygı düzeyleri ile dental alandaki uygulamalara (implant tedavisi türü) ilişkin kaygı düzeyi arasında tutarlı bir ilişki olduğunu göstermiş, bu yönüyle literatürdeki benzer çalışmalarla uyumlu bulunmuştur., ${ }^{4,7}$ Buna karşın, farklı sayıda implant uygulamasına tabi tutulan gruplar arasında psikolojik kaygı (durumluk ve sürekli kaygı) ve dental kaygı ölçeklerinden alınan puanlar açısından fark gözlenmemiştir. Buna göre, farklı sayıda implant uygulanan hastalar ile hiç implant uygulanmamış hastaların kaygı düzeyleri (özellikle DKÖ puanı açısından) arasında fark bulunmamıştır. Dental kaygı seviyesinin ve prevalansının belirlenmesi, diş hekimliği hizmetlerinin planlı, hızlı, ekonomik ve güvenilir gerçekleştirilebilmesi açısından önem taşımaktadır. Araştırmanın bulgularından hareketle, dental kaygı için risk oluşturan sosyodemografik özelliklerin bilinmesi, klinisyenlerin dental kaygısı olan hastaları için ayıracağı süreyi öngörüp, etkin bir tedavi planı oluşturabilmeleri ile kaygı düzeyi açısından fayda sağlayabileceği düşünülmektedir. 


\section{KAYNAKLAR}

1. Spielberger, CD. Current trends in theory and research on anxiety. Spielberger CD editör. Anxiety: Current trends in theory and research. 1972;2:3-19.

2. Öner N, Le Compte A. Durumluk-Sürekli Kaygı Envanteri El Kitabı (State-Trait Anxiety Inventory Handbook), 2th edn. Boğaziçi Üniversitesi Press, Istanbul; 1985.

3. López-Jornet P, Camacho-Alonso F, Sanchez-Siles M. Assessment of general pre and postoperative anxiety in patients undergoing tooth extraction: a prospective study. $\mathrm{Br} \mathrm{J}$ Oral Maxillofac Surg 2014;52:18-23.

4. Nicolas E, Collado V, Faulks D, Bullier B, Hennequin $M$. A national cross-sectional survey of dental anxiety in the French adult population. BMC Oral Health 2007;7:12.

5. do Nascimento DL, da Silva Araujo AC, Gusmao ES, Cimoes R. Anxiety and fear of dental treatment among users of public health services. Oral Health Prev Dent 2011; 9: 329-37.

6. Hermes D, Matthes M, Saka B. Treatment anxiety in oral and maxillofacial surgery. Results of a German multi-centre trial. J Craniomaxillofac Surg 2007;35:316-21.

7. Stabholz A, Peretz B. Dental anxiety among patients prior to different dental treatments. Int Dent J 1999 ;49:90-4.

8. Wong M, Lytle WR. A comparison of anxiety levels associated with root canal therapy and oral surgery treatment. J Endod 1991;17:461- 5.

9. Erten H, Akarslan ZZ, Bodrumlu E. Dental fear and anxiety levels of patients attending a dental clinic. Quintessence Int 2006;37:304-10.

10. Quteish Taani DS. Dental anxiety and regularity of dental attendance in younger adults. J Oral Rehabil 2002;29:604-8.

11.Esa R, Savithri V, Humphris G, Freeman R. The relationship between dental anxiety and dental decay experience in antenatal mothers. Eur J Oral Sci 2010;118:59-65.

12.Lorean A, Kablan F, Mazor Z, Mijiritsky E, Russe P, Barbu $\mathrm{H}$, et al. Inferior alveolar nerve transposition and reposition for dental implant placement in edentulous or partially edentulous mandibles: a multicenter retrospective study. Int J Oral Maxillofac Surg 2013;42(5):656-659.

13.Aktaş B, Ceylan G, Mumcu E, Aksüzek Ö, Ünalan F. Protetik tedavide yaşam kalitesi değerlendirme yöntemleri. İstanbul Üniversitesi Dişhekimliği Fakültesi Dergisi. 2009;43:1-2,59-65

14. Ergüven SS, Kılınç $Y$, Delilbaşı E, Işık B. Bir diş hekimliği fakültesi ağız, diş ve çene cerrahisi kliniğine başvuran hastaların dental kaygı düzeylerinin değerlendirilmesi. Acta Odontologica Turcica. 2015;32(1):7-11.

15. Oktay EA, Koçak MM, Şahinkesen G, Topçu FT. The role of age, gender, education and experiences on dental anxiety. Gulhane Med J. 2009;51:145-148.
16. Eli I, Schwartz-Arad D, Baht R, Ben-Tuvim H. Effect of anxiety on the experience of pain in implant insertion. Clinical oral implants research. 2003;14:115-118.

17.Bergdahl M, Bergdahl J. Temperament and character personality dimensions in patients with dental anxiety. Eur J Oral Sci 2003;111:93-8.

18. Morino M, Masaki C, Seo Y, Mukai C, Mukaibo T, Kondo Y, Shiiba S, Nakamoto T, Hosokawa R. Non-randomized controlled prospective study on perioperative levels of stress and dysautonomia during dental implant surgery.Journal of prosthodontic research. 2014;58: 177-183.

19.Wilson TD, McNeil DW, Kyle BN, Weaver BD, Graves RW. Effects of conscious sedation on patient recall of anxiety and pain after oral surgery. Oral Surg Oral Med Oral Pathol Oral Radiol. 2014;117:277-82.

20. Muğlalı M, Kömerik N. Ağız cerrahisi ve anksiyete. Cumhuriyet Üniversitesi Diş Hekimliği Fakültesi Dergisi. 2005;8:83-8.

21. Armfield J. M. Towards a better understanding of dental Anxiety and fear: Cognitions vs. experiences. Eur J Oral Sci. 2010;118:259-264

22.Zhang G, Hou R, Zhou H, Kong L, Ding Y, Qin R, et al. Improved sedation for dental extraction by using video eyewear in conjunction with nitrous oxide: a randomized, controlled, cross-over clinical trial. Oral Surg Oral Med Oral Pathol Oral Radiol. 2012;113:188-92.

23. Berge TI. Acceptance and side effects of nitrous oxide oxygen sedation for oral surgical procedures. Acta Odontol Scand. 1999;57:201-6.

Yazışma Adresi:

Zuhal ÖZATEŞ

Hacettepe Üniversitesi

Diş Hekimliği Fakültesi

Ağız, Diş ve Çene Radyolojisi AD.

Ankara, Türkiye

Tel : : +90312305 2205

E Posta: dtzuhalozates@gmail.com 